\title{
ANALISIS KEBUTUHAN POMPA UNTUK MINE DEWATERING KUARTAL III SUMP PIT 1 UTARA, BANKO BARAT, PT SATRIA BAHANA SARANA TANJUNG ENIM, PROPINSI SUMATERA SELATAN
}

\author{
ANALYSIS OF PUMP FOR MINE DEWATERING QUARTER III SUMP PIT 1 UTARA, BANKO \\ BARAT, PT SATRIA BAHANA SARANA TANJUNG ENIM, \\ PROVINCE OF SOUTH SUMATRA
}

\author{
Sepriadi ${ }^{1)}$,Sudarman ${ }^{2)}$ \\ 1Program Studi Teknik Pertambangan Batubara Politeknik Akamigas Palembang, 30257, Indonesia \\ 2Program Studi Teknik Pertambangan Batubara Politeknik Akamigas Palembang, 30257, Indonesia \\ Corresponding Author E-mail: sepri@pap.ac.id
}

\begin{abstract}
Coal is a non-renewable energy source that is widely used today. So that coal is in great demand by investors or entrepreneurs to establish companies, especially coal mining. PT Satria Bahana Sarana began operations in March 2015 as a mining contractor of PT Bukit Asam (Persero), Tbk. by using an open pit method with the operating area in Banko Barat 1 pit. Open pit mining will form a basin at the ground level and become one of the rainwater gathering places due to modification of surface topographic contours. Water entering the pit can come from rainwater or groundwater. In mining that is in PT Satria Bahana Sarana, the technical problems for water distribution in the mining pit are still a problem. Especially in sump drying in the North pit 1 with the actual volume of water $507786,46 \mathrm{~m}^{3}$ and catchment area of 74,61 ha which is still a calculation for the third quarter mining plan. In connection with the problems that exist, the author carries out the final assignment (TA) which is carried out directly in the field. Mine dewatering is an attempt to remove water that has entered the mining area which is usually carried out by pumping. Drying of the North sump pit can be dried for 122 days when using one DND 200 pump ( $Q=892,5 \mathrm{~m}^{3} /$ hour) and 51 days with the remaining water $-2,242 \mathrm{~m}^{3}$ from the actual volume sump $507786,46 \mathrm{~m}^{3}$ when using two pumps with a pipe diameter of 8 inch.
\end{abstract}

Keywords: Mining Method, Rainwater, Pumping

Abstrak: Batubara merupakan sumber energi yang tak terbaharukan yang banyak digunakan pada saat ini. Sehingga menjadikan batubara sangat diminati oleh para investor ataupun pengusaha untuk mendirikan perusahaan khususnya pertambangan batubara. PT Satria Bahana Sarana mulai beroperasi bulan Maret tahun 2015 sebagai mining contractor PT Bukit Asam (Persero), Tbk. dengan menggunakan metode penambangan terbuka (open pit) dengan wilayah operasi di pit 1 Banko Barat. Penambangan secara open pit akan membentuk cekungan pada permukaan tanah dan menjadi salah satu tempat berkumpulnya air hujan akibat modifikasi kontur topografi permukaan. Air yang masuk kedalam pit bisa berasal dari air hujan ataupun airtanah. Dalam penambangan yang ada pada PT Satria Bahana Sarana, masalah teknis untuk penyaliran air yang ada pada pit penambangan masih jadi permasalahan. Terutama dalam pengeringan sump pada pit 1 Utara dengan volume aktual air 507786,46 $\mathrm{m}^{3}$ dan catchment area seluas 74,61 ha yang sekarang masih jadi perhitungan untuk rencana penambangan kuartal III. Sehubungan dengan permasalahan yang ada, Penulis melakukan tugas akhir (TA) yang dilakukan secara langsung pengamatan dilapangan. Mine dewatering merupakan upaya untuk mengeluarkan air yang telah masuk ke daerah penambangan yang biasanya dilakukan dengan cara pemompaan. Pengeringan sump pit Utara dapat dikeringkan selama 122 hari apabila menggunakan satu pompa DND $200\left(Q=892,5 \mathrm{~m}^{3} / \mathrm{jam}\right)$ dan 51 hari dengan sisa air $-2,242 \mathrm{~m}^{3}$ dari volume aktual sump 507786,46 $\mathrm{m}^{3}$ apabila menggunakan dua pompa dengan diameter pipa 8 inch.

Kata Kunci : Metode Penambangan, Air Hujan, Pemompaan

\section{PENDAHULUAN}

\subsection{Latar Belakang}

Pada penambangan batubara di PT Satria Bahana Sarana ini kegiatan penambangan batubara (coal getting) dan penggalian lapisan tanah penutup (overburden) dilakukan dengan metode open pit. Penambangan secara open pit akan membentuk cekungan pada permukaan tanah dan menjadi salah satu tempat berkumpulnya air hujan akibat modifikasi kontur topografi 
permukaan. Air yang masuk kedalam pit bisa berasal dari air hujan ataupun air tanah.

Dalam penambangan yang ada pada PT Satria Bahana Sarana, masalah teknis untuk penyaliran air yang ada pada pit penambangan masih jadi permasalahan. Terutama dalam pengeringan sump pada pit 1 Utara yang sekarang masih jadi perhitungan untuk rencana penambangan kuarter III.

\subsection{Rumusan Masalah}

Penelitian ini dilakukan karena adanya permasalahan teknis untuk penyaliran air yang ada pada pit penambangan.Permaslahan tersebut terutama dalam pengeringan sump pada pit 1 Utara yang sekarang masih menjadi perhitungan untuk rencana penambangan kuarter III.

\subsection{Batasan Masalah}

Batasan masalah dalam penelitian ini, penulis hanya membahas dari segi kajian teknis penyaliran tambang untuk menentukan kebutuhan pompa yang diperlukan dalam mine dewatering kuarter III yang tepat menurut penulis untuk mengoptimalkan kegiatan penanganan sumpdi pit 1 Utara, Banko Barat PT Satria Bahana Sarana, Tanjung Enim, Propinsi Sumatera Sealatan.

\subsection{Tujuan Penelitian}

Tujuan dari penelitian ini adalah :

1. Menghitung curah hujan harian berdasarkan data curah hujan beberapa tahun sebelumnya.

2. Menghitung debit air yang masuk ke dalam sump berdasarkan curah hujan rencana yang teah dihitung sebelumnya.

3. Menghitung volume air aktual yang ada di sump pit 1 Utara.

4. Menentukan luas area tangkapan hujan di pit penambangan dan mendapatkan solusi untuk mengurangi tangkapan hujan di daerah tersebut.

5. Menganalisa kebutuhan pompa untuk mine dewateringsump agar sesuai rencana penambangan kuarter berikutnya.

\subsection{Manfaat Penelitian}

Manfaat dari penelitian ini adalah

1. Dapat mengetahui gambaran atau prediksi curah hujan yang akan datang.
2. Mengetahui seberapa besar debit air yang masuk dalam kurun waktu tertentu.

3. Mengetahui berapa volume air aktual yang ada di sump dan berada pada elevasi berapa.

4. Dapat mengetahui luas daerah tangkapan hujan (catchment area) pada sump di pit penambangan.

5. Mampu menentukan jumlah dan jenis pompa yang ideal untuk kebutuhan di sumppit 1 Utara.

\section{TEORI DASAR}

\subsection{Sistem Penyaliran Tambang}

Pengertian dari sistem penyaliran tambang adalah suatu usaha yang diterapkan pada daerah penambangan untuk mencegah, mengeringkan, atau mengeluarkan air yang masuk ke daerah penambangan. Upaya ini dimaksudkan untuk mencegah terganggunya aktifitas penambangan akibat adanya air dalam jumlah yang berlebihan, terutama pada musim hujan dan juga untuk memperlambat kerusakan pada alat, sehingga tahan lama (Suwandhi, 2004).

Sumber air yang masuk ke lokasi penambangan dapat berasal dari air permukaan tanah maupun air di bawah tanah. Air permukaan tanah merupakan air yang terdapat dan mengalir di permukaan tanah. Jenis air ini meliputi : air limpasan permukaan, air sungai, rawa atau danau yang terdapat di daerah tersebut, air buangan (limbah), dan mata air. Namun, air di bawah tanah merupakan air yang terdapat di bawah permukaan tanah (Gautama, 1999).

\subsection{Tujuan Penyaliran Tambang}

Meminimalkan air yang masuk ke dalam front penambangan serta mengeluarkan air dari area front penambangan (proses pemompaan). Untuk dapat melakukan pengendalian air tambang dengan baik perlu diketahui sumber dan perilaku air. Aspekaspek yang mendasari perencanaan penyaliran tambang adalah aspek hidrologi dan hidrogeologi, meliputi pengetahuan daur hidrologi, curah hujan, infiltrasi, air limpasan dan air tanah serta teknik penyaliran tambang (Suwandhi, 2004). 


\subsection{Metode Penyaliran Tambang}

Penanganan masalah air dalam suatu tambang terbuka dapat dibedakan menjadi dua, yaitu:

\section{Mine drainage}

Merupakan upaya untuk mencegah masuknya air ke daerah penambangan. Hal ini umumnya dilakukan untuk penanganan air tanah dan air yang berasal dari sumber air permukaan. Cara yang biasa digunakan untuk mencegah agar air permukaan adalah dengan membuat saluran/paritan di sekeliling tambang atau lantai jenjang.

\section{Mine dewatering,}

Merupakan upaya untuk mengeluarkan air yang telah masuk ke daerah penambangan. Upaya ini terutama untuk menangani air yang berasal dari air hujan.

Beberapa metode penyaliran tambang adalah sebagai berikut :

\subsection{Membuat Sump di Dalam Front Tambang (Pit)}

Sistem ini diterapkan untuk membuang air tambang dari lokasi kerja. Air tambang dikumpulkan pada sumuran (sump), kemudian dipompa keluar. Pemasangan jumlah pompa tergantung pada kedalaman penggalian, dengan kapasitas pompa menyesuaikan debit air yang masuk ke dalam lokasi penambangan.

\subsection{Membuat Paritan}

Pembuatan parit sangat ideal diterapkan pada tambang terbuka open cast atau kuari. Parit dibuat berawal dari sumber mata air atau air limpasan menuju kolam penampungan, langsung ke sungai atau diarahkan ke selokan (riool). Dimensi parit diukur berdasarkan volume maksimum pada saat musim penghujan deras dengan memperhitungkan kemiringan lereng. Bentuk standar melintang dari parit umumnya trapezium (Hartono, 2008).

\subsection{Faktor-faktor yang Mempengaruhi Sistem Penyaliran Tambang}

Faktor-faktor yang harus dipertimbangkan dalam merancang sistem penyaliran pada tambang terbuka (Hartono, 2008) adalah :

\section{Permeabilitas}

2. Rencana Kemajuan Tambang

3. Curah Hujan

Data curah hujan yang akan dianalisa adalah besarnya curah hujan harian maksimum. Pengolahan data curah hujan meliputi:

1. Periode ulang hujan

2. Hujan rencana

Salah satu metode dalam analisa frekuensi yang sering digunakan dalam menganalisa data curah hujan adalah metode distribusi ekstrim, atau juga dikenal dengan metode distribusi Gumbel (Suwandhi 2004).

Persamaan Gumbel tersebut adalah sebagai berikut:

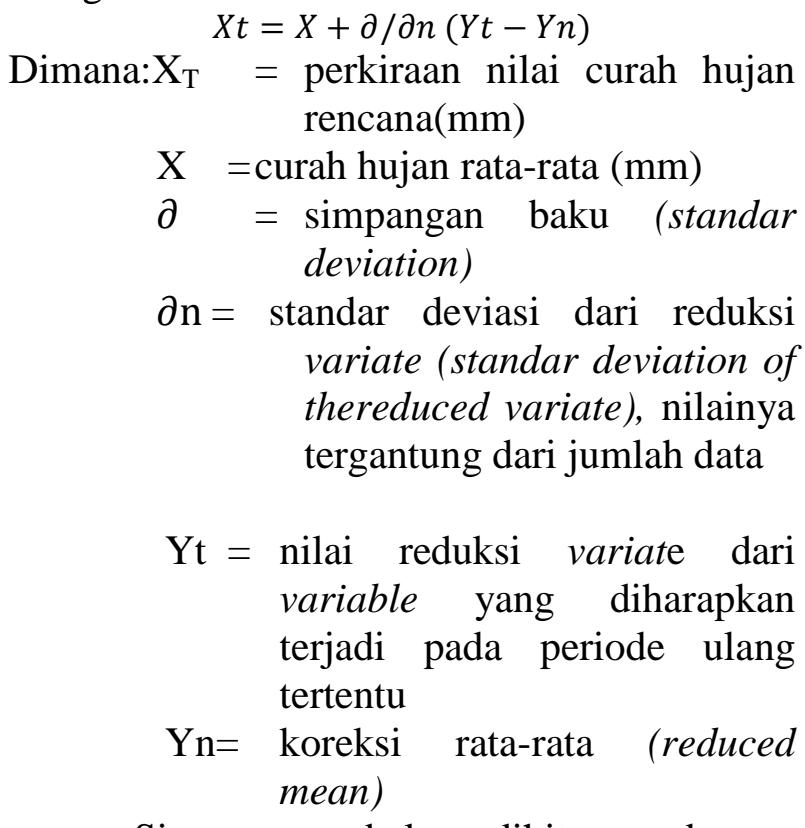
rumus :

Simpangan baku dihitung dengan

$$
\partial=\sqrt{\frac{\sum(X-\bar{X})^{2}}{n-1}}
$$

Dimana : $\partial=$ standar deviasi

$\mathrm{X}=$ nilai variat

$\overline{\mathrm{X}}=$ nilai rata-rata hitung variat

$\mathrm{n}=$ jumlah data

Nilai reduksi variat dihitung dengan menggunakan rumus :

$$
Y t=-\ln \left\{-\ln \left[\frac{T-1}{T}\right]\right\} .
$$

Dimana $: \mathrm{Y}=$ nilai reduksi variat dari variable yang diharapkan terjadi pada periode ulang tertentu

$\mathrm{T}=$ periode ulang (tahun) 
Koreksi rata-rata (reduced mean) dihitung dengan menggunakan rumus :

$$
Y n=-\ln \left[-\ln \left\{\frac{(n+1-m)}{n+1}\right\}\right]
$$

Dimana $: \mathrm{Yn}=$ koreksi rata-rata (reduced mean)

$\mathrm{n}=$ jumlah data

$\mathrm{m}=$ urutan data $(1,2,3, \ldots)$

Nilai koreksi simpangan (reduced standard deviation ) ditentukan dengan rumus:

$$
\partial n=\sqrt{\frac{\sum(Y n-\overline{Y n})^{2}}{n-1}}
$$

Dimana $: \partial \mathrm{n}=$ standar deviasi dari reduksi variate ( standar deviation of thereduced variate), nilainya tergantung dari jumlah data

$\mathrm{Yn}=$ koreksi rata-rata (reduced mean)

$\overline{\mathrm{Yn}}=$ nilai rata-rata $\mathrm{Yn}$

$\mathrm{n}=$ jumlah data

\section{Intensitas curah hujan}

Intensitas curah hujan adalah jumlah hujan per satuan waktu yang relatif singkat, dinyatakan dalam $\mathrm{mm} / \mathrm{jam}, \mathrm{mm} / \mathrm{menit}$, $\mathrm{mm} /$ detik. Perhitungan intensitas curah hujan satu jam dilakukan dengan menggunakan rumus Mononobe sebagai berikut (Suwandhi, 2004) :

$$
I=\frac{R_{24}}{24}\left(\frac{24}{T c}\right)^{\frac{2}{3}}
$$

Dimana $: R_{24}=$ curah hujan rencana perhari (24 jam)

$\mathrm{Tc}=$ waktu konsentrasi (jam)

4. Waktu konsentrasi

Waktu konsentrasi dapat dihitung dengan rumus :

$$
\mathrm{Tc}=\frac{\text { JamhujanMaksimal }}{\text { HariHujanMaksimal }}
$$

Dimana : Tc = waktu konsentrasi (jam)

\subsection{Air Limpasan}

Air limpasan adalah bagian dari curah hujan yang mengalir diatas permukaan tanah menuju sungai, danau atau laut.

Untuk memperkirakan debit air limpasan maksimal digunakan rumus rasional, yaitu :

$$
Q=C x I x A
$$

Dimana $: \mathrm{Q}=$ debit air limpasan maksimum $\left(\mathrm{m}^{3} /\right.$ detik $)$

$$
\begin{aligned}
\mathrm{C}= & \text { koefisien limpasan } \\
\mathrm{I}= & \text { intensitas curah hujan (m/detik) } \\
\mathrm{A}= & \text { luas daerah tangkapan hujan } \\
& \left(\mathrm{m}^{2}\right)
\end{aligned}
$$

\subsection{Catchment Area}

Catchment area (daerah tangkapan air) merupakan suatu wilayah daratan yang merupakan satu kesatuan dengan sungai dan anak-anak sungainya, yang berfungsi menampung, menyimpan, dan mengalirkan air yang berasal dari curah hujan ke danau atau ke laut secara alami, yang batas di darat merupakan pemisah topografis yang dapat berupa punggung-punggung bukit atau gunung dan batas di laut sampai dengan daerah perairan yang masih terpengaruh aktifitas daratan.

\subsection{Sump}

Sump merupakan bagian yang tidak dapat dipisahkan dalam sistem tambang terbuka. Sump berfungsi sebagai penampung segala jenis air yang masuk ke dalam pittambang terbuka. Sumber air pada sistem tambang terbuka meliputi air hujan, air permukaan, limpasan/rembesan dari sumber air permukaan dan airtanah. Dalam perjalanan suatu sistem tambang terbuka, pengelolaan sump merupakan suatu keharusan.

\subsection{Pemompaan}

Pompa berfungsi untuk memindahkan atau mengeluarkan air dari tempat yang rendah, yaitu air yang ada pada kolam penampungan (sump) pada lantai kerja penambangan ke tempat yang lebih tinggi (keluar tambang). Sesuai dengan prinsip kerjanya, pompa dibedakan atas :

1.Reciprocating Pump

2.Centrifugal Pump

3.Axial Pump

Dalam pemompaan dikenal istilah julang (head), yaitu energi yang diperlukan untuk mengalirkan sejumlah air pada kondisi tertentu. Semakin besar debit air yang dipompa, maka head juga akan semakin besar. Head total pompa untuk mengalirkan sejumlah air seperti yang direncanakan dapat ditentukan dari kondisi instalasi yang akan dilayani oleh pompa tersebut, sehingga julang total pompa dapat dituliskan sebagai berikut: 


$$
\mathrm{H}=h_{s}+h_{v}+h_{f 1}+h_{f 2}
$$

Dimana $: \mathrm{H}=$ head total pompa (m)

$\mathrm{h}_{\mathrm{s}}=$ headstatis pompa (m)

$\mathrm{h}_{\mathrm{v}}=$ head kecepatan $(\mathrm{m})$

$\mathrm{h}_{\mathrm{f} 1}=$ head gesekan $(\mathrm{m})$

$\mathrm{h}_{\mathrm{f} 2}=$ head belokan

Perhitungan berbagai julang pada

pemompaan :

1. Head statis $\left(\mathrm{h}_{\mathrm{s}}\right)$

$$
h s=h_{2}-h_{1}
$$

Dimana $: \mathrm{h}_{1}=$ elevasi sisi isap $(\mathrm{m})$

$\mathrm{h}_{2}=$ elevasi sisi keluar $(\mathrm{m})$

2. Head kecepatan

$$
h_{V}=\frac{V^{2}}{2 g}
$$

Dimana $: \mathrm{Hv}=$ head kecepatan $(\mathrm{m})$

$$
\mathrm{v}=\underset{(\mathrm{m} / \text { detik })}{\operatorname{kecepatan} \text { aliran air dalam pipa }}
$$

3. Head gesekan $\left(\mathrm{h}_{f 1}\right)$

$$
H f 1=f\left(\frac{L v^{2}}{2 D g}\right)
$$

Dimana : $\mathrm{Q}=$ debit air limpasan $\left(\mathrm{m}^{3} /\right.$ detik)

$\mathrm{v}=$ kecepatan aliran dalam pipa (m/detik)

$\mathrm{L}=$ panjang pipa $(\mathrm{m})$

$\mathrm{d}=$ diameter pipa $(\mathrm{m})$

$\mathrm{f}=$ koefisien kekasaran pipa

$\mathrm{g}=$ percepatan gravitasi bumi $\left(\mathrm{m} / \mathrm{detik}^{2}\right)$

4. Head belokan $\left(\mathrm{h}_{f 2}\right)$

$$
h_{f 2}=k\left(\frac{v^{2}}{2 g}\right)
$$

Dimana $: \mathrm{k}=$ koefisien kerugian pada belokan

$$
\begin{gathered}
\mathrm{k}=\left[0,131+1,847\left(\frac{\mathrm{D}}{2 \mathrm{R}}\right)^{3,5}\right] \times\left(\frac{\theta}{90}\right)^{0,5} \\
\mathrm{~V}=\begin{array}{l}
\text { kecepatan aliran dalam pipa } \\
\left(\mathrm{m} / \text { detik }^{2}\right.
\end{array} \\
\mathrm{g}=\begin{array}{l}
\text { percepatan } \\
\left(\mathrm{m} / \text { detik }^{2}\right)
\end{array} \text { gravitasi bumi } \\
\mathrm{R}=\begin{array}{c}
\text { jari-jari lengkung belokan }(\mathrm{m}) \\
R=\frac{D}{\tan \frac{1}{2} \theta}
\end{array} \\
\mathrm{\Theta}=\text { sudut belokan pipa (derajat) } \\
\mathrm{D}=\text { diameter pipa }(\mathrm{m})
\end{gathered}
$$

\subsection{Saluran Penyaliran}

Perhitungan kapasitas pengaliran suatu saluran air dilakukan dengan rumus manning ( Amin, 2000) sebagai berikut :

$$
\begin{aligned}
Q & =1 / n \times R^{2 / 3} \times S^{1 / 2} \times A \\
\text { Dimana : Q } & =\operatorname{debit}\left(\mathrm{m}^{3} /\right. \text { detik) } \\
\mathrm{R} & =\text { jari-jari hidrolik }(\mathrm{m}) \\
\mathrm{S} & =\text { kemiringan saluran }(\%) \\
\mathrm{A} & =\text { luas penampang basah }\left(\mathrm{m}^{2}\right) \\
\mathrm{n} & =\text { koefisien kekasaran manning }
\end{aligned}
$$

\section{METODOLOGI PENELITIAN}

\subsection{Jenis Penelitian}

Jenis penelitian yang dilakukan pada adalah penelitian kuantitatif dengan proses penelitiannya langsung melakukan observasi ke lapangan.

\subsection{Waktu dan Tempat Penelitian}

Kegiatan yang dilakukan untuk pengambilan data ini dilaksanakaan pada tanggal 5 Mei 2017 s.d. 5 Juni 2017 di area pit 1 Utara PT Satria Bahana Sarana Distrik Banko Barat jobsite Tanjung Enim.

\subsection{Metode Penelitian}

Masalah-masalah yang dibahas pada penelitian ini, dapat menggunakan beberapa metode penyelesaiannya sebagai berikut :

1. Studi literatur

Studi literatur dilakukan dengan mencari informasi serta teori yang berhubungan dengan kondisi jalan angkut berdasarkan referensi dari handbook, dan dari sumber referensi lainnya.

2. Observasi

Penelitian ini dilakukan secara langsung dengan mengamati lokasi di di area pit 1 Utara PT Satria Bahana Sarana terkait dengan akan dibahas, antara lain :

a. Pengamatan daerah tangakapan hujan pit 1 Utara dan menentukan daerah lokasi pengambilan data di daerah sump.

b. Pengamatan saluran easting dan pengukuran volume air sump.

3. Pengambilan data

Pengambilan data tergantung dari jenis data yang dibutuhkan, yaitu

a. Data sekunder, antara lain :tinjauan umum PT Satria Bahana Sarana, data curah hujan, spesifikasi pompa dan 
grafik rpmpompa DND 200, danjenis pipa yang digunakan.

b. Data primer, antara lain :penentuan langsung daerah tangkapan hujan, pengukuran debit air keluar dari hasil pemompaan aktual, pengukuran dan perhitungan volume air aktual di sump pit 1 Utara

4. Pengumpulan data

Data yang akan diambil dan dikumpulkan kemudian di klasifikasikan berdasarkan jenis data kemudian dilakukan perhitungan secara teoritis sesuai dengan kebutuhan dan tujuan penelitian.

5. Pengolahan data

Pengolahan data yang dilakukan dalam penelitian ini mengunakan metode statistik untuk menghitung curah hujan, intensitas hujan pada penelitian dan mengunakan teori-teori yang dikemukan oleh parah ahli tambang.Pengambilan kesimpulan

Kesimpulan diambil dari hasil pengolahan data dengan membandingkan opsi-opsi yang sudah diambil dan dianalisa dan selanjutnya memberikan rekomendasi yang mendasar pada perusahaan terkait.

\section{HASIL DAN PEMBAHASAN}

\subsection{Kondisi Aktual Dewatering Pit 1 Utara PT Satria Bahana Sarana}

Dalam kegiatan penambangan batubara di pit 1 utara PT Satria Bahana Sarana menggunakan sumpuntuk menampung presipitasi air hujan. Terdapat satu buah pompa pada pit utara yang terletak di pit penambangan batubara. Pompa yang digunakan mengalirkan air ke luar sumpdiarahkan menuju kolam pengendapan lumpur.

Kondisi di lapangan berdasarkan pengamatan penulis, kinerja dan penanganan dewatering masih belum maksimal. Karena, dilihat dari lokasi penambangan batubara masih ada genang air. Untuk itu, perlu penanganan pit dewatering pada pit 1 utara PT Satria Bahana Sarana.

\subsection{Analisis Data Curah Hujan}

\subsubsection{Metode Distribusi Gumble}

Penentuan data curah hujan didapatkan dari perhitungan data curah hujan sebelumnya yang diambil sepuluh tahun sebelumnya, yaitu data curah hujan tahun 2007 sampai 2016. Analisis curah hujan rencana ditentukan dengan metode umum yang sering digunakan dalam merencanakan curah hujan. Metode Gumble dipakai untuk menentukan distribusi curah hujan yang mungkin terjadi di daerah penelitian.Hujan rencana ini ditentukan dari hasil analisis frekuensi data curah hujan yang tersedia dengan menggunakan metode partial duration series, yaitu dengan mengambil dan mencatat curah hujan maksimum periode 2007-2016. Berdasarkan data curah hujan, diperoleh data curah hujan rata-rata untuk kuarter III $121 \mathrm{~mm} / \mathrm{hari}$, dan curah hujan maksimum pada kuarter III terjadi pada bulan September tahun 2017 dengan curah hujan tertinggi sebesar $454 \mathrm{~mm} / \mathrm{hari}$.

Berdasarkan perhitungan dengan metode distribusi Gumbledidapatkan nilai curah hujan rencana sebesar 138,596 $\mathrm{mm} / \mathrm{bulan}$ yang artinya nilai ini lebih kecil daripada nilai rata-rata curah hujan bulanan pada kuarter III. Maka dengan pertimbangan pesimis digunakan curah hujan tertinggi pada kuarter III, yaitu $138.596 \mathrm{~mm} / \mathrm{hari}$ untuk mengantisipasi kelebihan debit yang disebabkan kesalahan dalam perhitungan penentuan curah hujan rencana pada kuarter III tahun 2016.

\subsubsection{Perhitungan Debit Air Limpasan}

Debit air limpasan merupakan perkalian antara curah hujan rencana dalam pit dapat dihitung dengan memperhitungkan parameter berikut ini. parameter waktu konsentrasi, intensitas curah hujan, koefisien air limpasan dan catchmentarea.

1). Waktu konsentrasi

Waktu konsentrasi air hujan diambil dari pembagian antara jam hujan maksimal pada kuarter II dua tahun sebelumnya dengan banyak hari hujan maksimal kuarter II dua tahun sebelumnya.Waktu konsentrasi maksimal yang didapatkan dari perhitungan sebesar 4,57 jam/hari pada kuarter III. 
2). Intensitas curah hujan

Intesitas curah hujan yang terjadi pada daerah penambangan pit 1 utara adalah sebesar 2,12 $\mathrm{mm} / \mathrm{jam}$.Debit air limpasan yang masuk ke dapat sump 1 sebesar $1423,5588 \mathrm{~m}^{3} / \mathrm{jam}$ atau sebesar 1.423.558,8liter/jam.

\subsubsection{Evapotranspirasi}

Evapotranspirasi yang terjadi pada sump di pit 1 utara kemungkinan terjadi sangat kecil dan tidak berpengaruh terhadap volume dan debit air pada sump pit 1 utara. Evapotranspirasi dapat terjadi pada area basah sump namun dari hasil pengamatan dan perhitungan, maka evapotranspirasi tidak digunakan dalam perhitungan untuk menjaga keyakinan debit yang masuk ke dalam sump.

\subsection{Daerah Tangkapan Hujan}

\subsubsection{Catchment Area Sump pit 1 Utara}

Daerah tangkapan hujan atau catchmentarea pada kuarter II dan kuarter III tahun 2017, berdasarkan peta kemajuan tambang memperlihatkan daerah tangkapan hujan sangat dipengaruhi oleh kontur wilayah. Daerah tangkapan hujan pada kuarter II dan III tahun 2017 pada blok penambangan pit 1 Utara PT Satria Bahana Sarana seluas 74,61ha.

Area tangkapan hujan pada pit 1 Utara diasumsikan memiliki koefesien limpasan 0,9 dimana air yang melimpas di permukaan sebesar $90 \%$ dan air hujan yang diserap oleh permukaan tanah sebesar $10 \%$.

\subsubsection{Penentuan Daerah Tangkapan Hujan}

Daerah tangkapan hujan pada pit 1 Utara tambang PT Satria Bahana Sarana didapatkan dengan cara mengambil beberapa titik-titik batas daerah tangkapan hujan dengan menggunakan alat GPS dan melakukan marking. Pada kegiatan ini GPS yang digunakan adaah GPS tipe Garmin GPSMAP $64 S$. Koordinat titik-titik yang diambil dengan menggunakan GPS meliputi nilai $\mathrm{x}, \mathrm{y}$, z. yang didefenisikan sebagai batas daerah tangkapan hujan di lapangan kemudian diolah dengan menggunakan software minescape.

Volume air pada sump pit 1 Utara sekarang ini adalah 507786,46 $\mathrm{m}^{3}$. Perhitungan tersebut volume air pada sump didapatkan atas perhitungan menggunakan software minescape dengan menggunakan situasi terbaru dari pit 1 Utara.

\subsection{Debit Pemompaan Air Sump}

Pada PT Satria Bahana Sarana pengecekan debit air pada pompa dilakukan sebanyak dua kali, yakni dilakukan pada pagi dan sore hari. Pemompaan air pada sump dilakukan selama 24 jam yang dimulai dari jam 06.00 WIB - 06.00 WIB. Untuk pemompaan dilakukan dengan $1250 \mathrm{rpm}$ yang merupakan ketetapan dari PT Satria Bahana Sarana.

Dari pengukuran kecepatan air sump menggunakan alat flow meter untuk pipa saluran dengan diameter 8 inch $(0,2032 \mathrm{~m})$ diketahui kecepatan debit air pada pipa outletsump menuju kolam pengendapan seperti pada tabel 4.1.

Tabel 4.1Kecepatan Debit Pemompaan AirSump

\begin{tabular}{|c|c|c|c|c|}
\hline Hari ke- & $\mathrm{V}(\mathrm{m} / \mathrm{s})$ & $\mathrm{A}\left(\mathrm{m}^{2}\right)$ & $\begin{array}{c}\mathrm{Q} \\
\left(\mathrm{m}^{3} / \mathrm{s}\right)\end{array}$ & $\mathrm{Q}\left(\mathrm{m}^{3} / \mathrm{jam}\right)$ \\
\hline 1 & 2,7 & 0,032 & 0,088 & 315,053 \\
\hline 2 & 2,9 & 0,032 & 0,094 & 338,390 \\
\hline 3 & 3 & 0,032 & 0,097 & 350,059 \\
\hline 4 & 3,4 & 0,032 & 0,110 & 396,733 \\
\hline 5 & 3,5 & 0,032 & 0,113 & 408,402 \\
\hline 6 & 3,3 & 0,032 & 0,107 & 385,065 \\
\hline 7 & 2,7 & 0,032 & 0,088 & 315,053 \\
\hline 8 & 3 & 0,032 & 0,097 & 350,059 \\
\hline 9 & 3 & 0,032 & 0,097 & 350,059 \\
\hline 10 & 3,3 & 0,032 & 0,107 & 385,065 \\
\hline
\end{tabular}

Pada kolam penampungan (sump) pit 1 Utara berdasarkan data tahun 2017 menunjukkan variasi ketinggian air yang mengikuti pergantian musim hujan dan kemarau pada tiap tahunnya. Bulan basah terjadi pada bulan Nopember sampai dengan April sedangkan bulan kering terjadi pada bulan Mei - Oktober 2017.

Perkiraan debit air yang masuk ke sump dan front penambangan diasumsikan berasal dari air limpasan (run off). Dimana curah hujan rencana yang dipakai dalam 
perencaan sebesar $\mathrm{mm} / \mathrm{jam}$. Perhitungan curah hujan menggunakan metode distribusi curah hujan Gumble.

\subsubsection{Kolam Penampungan (Sump)}

Kolam penampungan yang ada pada pit 1 utara hanya ada satu. Didalam perencananya apabila sump pada pit Utara ini kering akan dilakukan penambangan guna untuk mengambil batubara yang ada di bawah sump tersebut. Pada sumppit 1 Utara ini dapat menampung volume air sebesar $150.000 \mathrm{~m}^{3}$ pada elevasi permukaan air mencapai 65 meter. Pada saat ini kolam penampungan pada pit 1 Utara, menampung air pada elevasi 13,6 meter. Pompa pada sump pit 1 Utara hanya menggunakan satu pompa jenis DND 200 dari PT KSB. Air yang ada pada sump pit 1 Utara ini berasal dari air rembesan atau air tanah dan air limpasan air hujan. Untuk mengetahui situasi sump pada pit 1 Utara ini.

\subsection{PengeringanSumpPit 1 Utara}

\subsubsection{Pemompaa Sump Pit 1 Utara (Actual)}

Pompa yang digunakan pada sistem pemompaan adalah pompa DND 200, dengan debit maksimal $892,5 \mathrm{~m}^{3} / \mathrm{jam}$ atau 14.875 $\mathrm{m}^{3} /$ menit. Pompa dipasang pada elevasi $10 \mathrm{~m}$ dan outlet pemompaan berada pada elevasi 60 meter.

Total Head pada pompa jika bekerja pada debit pemompaan maksimal yang terjadi dalah sebesar 97,765 $\mathrm{m}$ dengan panjang pemipaan sejauh $360 \mathrm{~m}$. Pompa DND 200 akan bekerja pada beberapa variasi rpm dan efisiensi sesuai dengan debit air yang dipompakan oleh pompa. Pompa DND 200 bekerja pada debit aktual pemompaan sebesar $315,89 \mathrm{~m}^{3} / \mathrm{jam}$ dengan $\mathrm{rpm} 1050$ dengan jam produktif pemompaan 17,3 jam/hari.

\subsubsection{Pemompaan Sump Pit 1 Utara Rekomendasi (Recommended)}

Untuk memperlihatkan rpm rekomendasi dan efisiensi pompa, maka dilakukan plotting debit air dengan total head hasil perhitungan didapatkan nilai rpm dan efisiensi seperti yang ditunjukkan pada tabel 4.2.
Tabel 4.2Hasil Ploting Rpm dan Efisiensi Pompa Diameter Pipa 8 Inch Recommended SumpPit 1 Utara

\begin{tabular}{|c|c|c|c|}
\hline $\begin{array}{c}\text { Duty of } \\
\text { Flowrate } \\
\text { (liter/detik) }\end{array}$ & $\begin{array}{c}\text { Duty of } \\
\text { Total } \\
\text { Head }(\mathrm{m})\end{array}$ & $\begin{array}{c}\text { Rpm } \\
\text { Recommended } \\
(\mathrm{rpm})\end{array}$ & $\begin{array}{c}\text { Efisiensi } \\
\text { Pompa } \\
(\%)\end{array}$ \\
\hline 86,111 & 58,36 & 950 & 60 \\
\hline 83,333 & 57,83 & 900 & 60 \\
\hline
\end{tabular}

Berdasarkan perhitungan didapatkan nilai efisiensi dari pompa DND 200 untuk digunakan sebagai rekomendasi dalam penentuan debit air yang dipompakan keluar sump sebesar 83,33 Liter/detik dengan efisiensi pompa sebesar $60 \%$ dengan rpm 950 akan menghasilkan debit pompa $310 \mathrm{~m}^{3} / \mathrm{jam}$. Dimana berdasarkan standar yang ditetapkan bahwa efisiensi minimal pompa $60 \%$.

Dibandingkan dengan debit pemompaan pompa DND 200 secara aktual yang menggunakan rpm 1050 dengan debit pemompaan yang dihasilkan sebesar 315,89 $\mathrm{m}^{3} / \mathrm{jam}$, maka direkomendasi rpm pemompaan pompa DND 200 dengan rpm 950 yang dapat menghasilkan debit pemompaan yang hampir setara, yaitu sebesar $310 \mathrm{~m}^{3} / \mathrm{jam}$. Selain itu efisiensi pemompaan secara aktual dengan pemompaan yang direkomendasikan sama, yaitu $70 \%$ dan daya poros pompa sebesar 30 kw.

Pada pengeringan sump pit 1 Utara dapat dilakukan dengan cara penyesuaian rpm dan diameter pipa yang digunakan pada pompa. Dari hasil penelitian didapatkan data bahwa sump pit 1 Utara dapat dikeringkan selama 122 hari dengan sisa air $-3,617 \mathrm{~m}^{3}$ dari volume total air sump aktual sebanyak $507786,46 \mathrm{~m}^{3}$ yang jatuh pada bulan Oktober tahun 2017, apabila menggunakan satu pompa DND 200 dengan diameter pipa HDPE 8 inch. Untuk rpm pompa yang digunakan sebesar 950, efisiensi sebesar $70 \%$ dengan debit pemompaan $310 \mathrm{~m}^{3} / \mathrm{jam}$ dan jam pemompaan 17,3 jam/hari.

Sedangkan apabila menggunakan dua pompa dengan rpm, efisiensi, debit dan diameter pipa yang sama, sump pit 1 Utara dapat dikeringkan selama 51 hari dengan sisa 
air $-2,242 \mathrm{~m}^{3}$ dari volume air aktual, yang jatuh pada bulan Agustus tahun 2017.

Kemudian sump pit 1 Utara dapat juga dikeringakan lebih cepat dari penggunaan rekomendasi rpm dan diameter pipa diatas. Dimana disini, sump direkomendasikan menggunakan rpm sebesar 1010dengan efisiensi sebesar $71 \%$ dan debit pemompaan yang dihasikan sebesar $577 \mathrm{~m}^{3} / \mathrm{jam}$ dan waktu pemompaan 17,3 jam/hari dapat dilihat pada tabel 4.3.

Dari hasil rekomendasi tabel di atas sump pit 1 Utara dapat dikeringkan selama 55 hari dengan sisa air $-2,067 \mathrm{~m}^{3}$ apabila menggunakan satu pompa DND 200 dan diameter yang digunakan 10 inch dengan rpm. Sedangkan apabila menggunakan dua pompa DND 200 dengan rekomendasi rpm dan diameter pipa yang sama, pengeringan sump pit 1 Utara dapat dilakukan selama 27 hari dengan sisa air $-11,076 \mathrm{~m}^{3}$ dan terjadi pada bulan Juli tahun 2017.

Tabel 4.3Hasil Ploting Rpm dan Efisiensi Pompa Diameter Pipa 10 Inch Recommended SumpPit 1 Utara

\begin{tabular}{|c|c|c|c|}
\hline $\begin{array}{c}\text { Duty of } \\
\text { Flowrate } \\
\text { (liter/detik) }\end{array}$ & $\begin{array}{c}\text { Duty of } \\
\text { Total } \\
\text { Head } \\
(\mathrm{m})\end{array}$ & $\begin{array}{c}\text { Recommended } \\
\text { (rpm) }\end{array}$ & $\begin{array}{c}\text { Efisiensi } \\
\text { Pompa } \\
(\%)\end{array}$ \\
\hline 216,67 & 68,40 & 1020 & 73 \\
\hline 208,33 & 67,01 & 1010 & 71 \\
\hline 177,78 & 62,39 & 980 & 71 \\
\hline
\end{tabular}

Jadi, apabila sump pit 1 Utara ingin cepat dikeringkan untuk penambangan kuarter III, perusahaan harus menggunakan dua buah pompa jenis DND 200 dengan rpm yang telah direkomendasikan di atas dengan menggunakan diameter pipa HDPE 10 inch.

\section{KESIMPULAN DAN SARAN}

\subsection{Kesimpulan}

Dari pembahasan tersebut, maka kesimpulan dari penelitian ini, yaitu :

1. Luas daerah tangkapan hujan (catchment area) pada sump pit 1 Utara adalah sebesar74,61 ha atau sekitar $746.100 \mathrm{~km}^{2}$.
2. Debit air limpasan yang masuk ke dapat sumppit 1 utara sebesar $1423,5588 \mathrm{~m}^{3} / \mathrm{jam}$ atau sebesar 1.423.558,8 liter/jam.

3. Dari hasil pengolahan data curah hujan yang ada dari tahun 2007 sampai tahun 2016 diperoleh curah hujan perkiraan maksimum untuk masa ulang hujan dua tahun sebesar 16,88 mm/jam dan intensitas hujan sebesar 2,12 mm/jam.

4. volume air pada sump pit 1 Utara sekarang ini adalah 507786,46 $\mathrm{m}^{3}$ dam berada pada elevasi 13,6 m.

1. Pengeringan sump pit 1 Utara dapat dilakukan dengan cara melakukan penggunaan rpm dan diameter yang lebih tepat dengan jenis pompa tipe DND 200.

\subsection{Saran}

Saran yang dapat diberikan dari penelitian ini, yaitu :

1. Pada penggunaan pipa HDPE, sebaiknya menggunakan pipa yang berdiameter sesuai ( $>8$ inch) dengan pompa tipe DND 200 yang memiliki debit pemompaan maksimal 892,5 $\mathrm{m}^{3} / \mathrm{jam}$.

2. Dalam upaya pengeringan sump pit 1 Utara yang direncanakan untuk penambangan kuarter III sebaiknya menggunakan minimal dua pompa jenis DND 200 bukan satu pompa.

3. Untuk penggunaan rpm dan efisiensi pompa sebaiknya digunakan rpm yang sesuai melalui perhitungan dan pertimbangan.

4. Paritan yang telah rusak sebaiknya dilakukan perbaikan segera agar air limpasan tidak merembes ke front penambangan yang dapat mengganggu kelancaran produksi.

5. Untuk jam kerja pemompaan sebaiknya dilakukan penambahan jam kerja, dimana yang secara aktual jam pemompaan adalah $15 \mathrm{jam} / \mathrm{hari}$

\section{DAFTAR PUSTAKA}

Gautama., RS.. 1999.Sistem Penyaliran Tambang. Institut Teknologi Bandung. 
Mine Plan PT Satria Bahan Sarana. 2017. Dokumen Mine Plan. PT Satria Bahana Sarana.

PT KSB Indonesia. 2017. Spesifikasi Poma DND 200 dan Grafik RPM. PT Satria Bahana Sarana.

Suwandhi, A.. 2004.Perencanaan Sistem Penyaliran Tambang. Universitas Islam Bandung. 
P-ISSN: 2089-5925 E-ISSN: 2621-9328

tintrant

Jurnal Teknik Patra Akademika

PA

A KaAemiKa

Volume 09 No 01 Juli 2018 